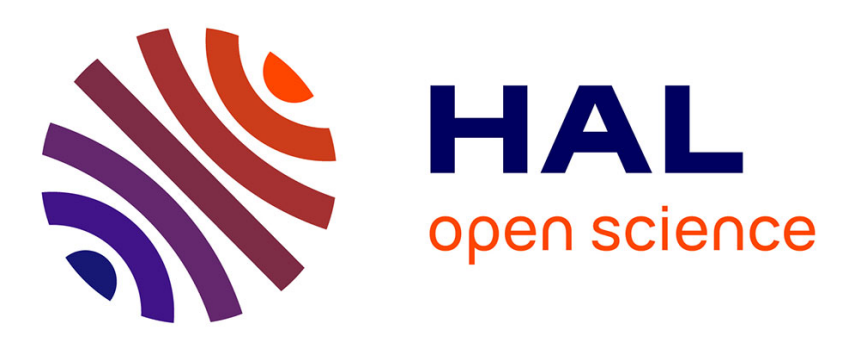

\title{
Detection of Defects in Road Surface by a Vision System
}

Tien Sy Nguyen, Manuel Avila, Stéphane Begot, Jean-Christophe Bardet

\section{To cite this version:}

Tien Sy Nguyen, Manuel Avila, Stéphane Begot, Jean-Christophe Bardet. Detection of Defects in Road Surface by a Vision System. Electrotechnical Conference, The 14th IEEE Mediterranean, 2008, AJACCIO, France. pp.847 - 851. hal-00666928

\section{HAL Id: hal-00666928 \\ https://hal.science/hal-00666928}

Submitted on 7 Feb 2012

HAL is a multi-disciplinary open access archive for the deposit and dissemination of scientific research documents, whether they are published or not. The documents may come from teaching and research institutions in France or abroad, or from public or private research centers.
L'archive ouverte pluridisciplinaire HAL, est destinée au dépôt et à la diffusion de documents scientifiques de niveau recherche, publiés ou non, émanant des établissements d'enseignement et de recherche français ou étrangers, des laboratoires publics ou privés. 


\title{
Detection of Defects in Road Surface by a Vision System
}

\author{
N. T. Sy$^{* \dagger}$ M. Avila*, S. Begot* and J. C. Bardet* \\ *PRISME Institute-MCDS Team - Orleans University - IUT Chateauroux - France \\ $\dagger$ ) Vectra Road Engineering - Buzancais - France \\ Email: nguyen.tiensy@yahoo.com
}

\begin{abstract}
This paper presents a real-time method for crack detection used in our apparatus of road characterisation AMAC@. The method based on a set of image processing tasks : bi-level thresholding, morphological operation, and projection. The method have been tested on three kinds of images: the first ones are images taken in laboratory in static mode and 'ideal' lighting condition, the second ones are static images taken by a normal camera in static mode without control of lighting condition and the third ones are images acquired by

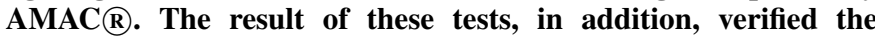

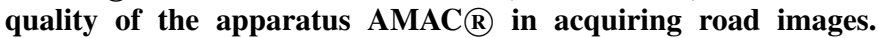

Index Terms-Edge detection, defect detection, pavement cracks detection, quality control, road inspection, texture analysis.

\section{INTRODUCTION}

$\mathbf{T}$ HE detection of defects in road surfaces is necessary for keeping a well maintained of road network. In the past, the detection of road defects was done visually by a technician driving along the road at speed of 5 to 10 kilometers per hour using an on board data acquisition device. By this way, vehicule speed of the data acquisition, the safety of qualified staff and road users were not satisfied at all [1]. To resolve this problem, some devices for monitoring condition of road surface speedly, with better quality of data acquired were developed. Some such devices are CSIRO's road crack detection vehicle [2], and Roadware's WiseCrax, crack detection system [3]. Unfortunately, by the commercial nature of these systems, information on their algorithms of image processing for the crack detection are limited. In addition, by the difference of the pavement of road in France, these systems do not satisfy the requirements for road maintenance. The maintenance of road in France requires information about the cracks as small as $1 \mathrm{~mm}$ wide.

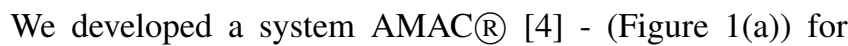
characterisation of roads in France, one of its functions is acquisition of road images in high resolution and independently of lighting conditions. Data acquisition is performed with two line scan cameras mounted on the vehicule with an angle of approximately 30 degrees, the road surface is illuminated by two laser illuminators (Fig. 1(b)), thus the time of day, varying

This work was supported by Regional Council of Centre, France and Vectra Road Engineering Company, Buzancais, France

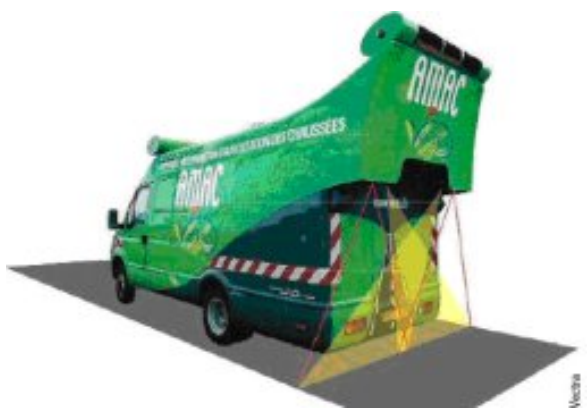

(a)

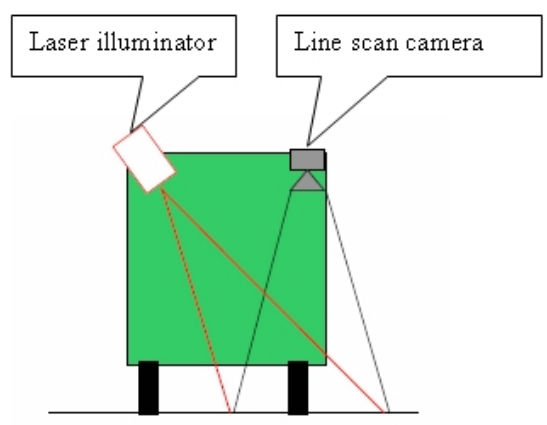

(b)

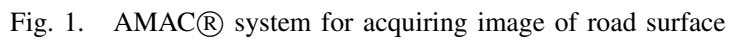

light conditions and shadows over the road have almost no effect on the quality of the acquired data.

The vehicle works at average speed of 80 kilometers per hour (to meet the requirement of speed limitations in highway and motorway). The resolution of acquired image is $1 \mathrm{~mm}$ per pixel, the size of road captured by each image is $3.9 \mathrm{~m}$ width and $4 \mathrm{~m}$ long, corresponding to the average size of $4096 \times 4096$ pixels, 8 bits grey level image. Each second, about 5 images of this large size must be stored, it means that about one terabyte of images are stored in each session of acquisition. In fact, by our experience of data exploration, nearly $60 \%$ of these images do not contain any default.

Actually, the data processing is done offline, the detection of defect is performed totally manually by an operator viewing images on screens. 


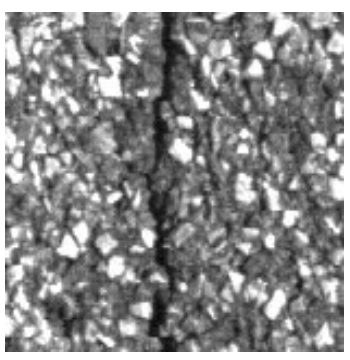

(a)

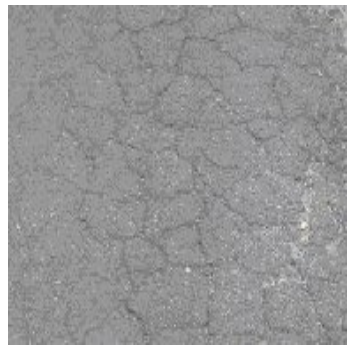

(c)

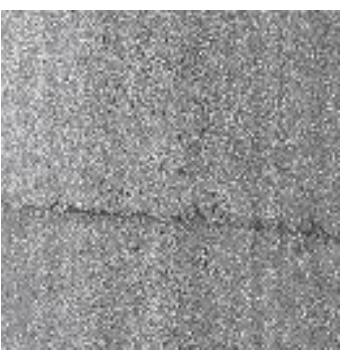

(b)

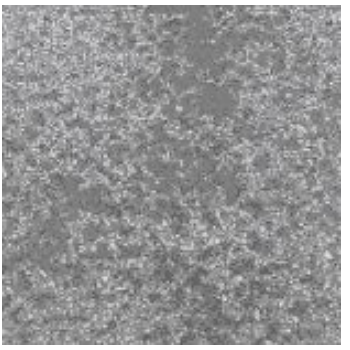

(d)
Fig. 2. Some examples of road defect: Longitudinal crack (a), transversal crack (b), alligator crack (c), bleeding (d)

There are different kinds of defects that may be detected, some of them are shown in (Fig. 2). Cracking defect is particularly interesting amoung the defects of road. Cracks should be detected as soon as possible for doing the maintenance before they develop into more serious problem. In this work, we limit our study to defect of crack type (Fig. 2(a), 2(b) and 2(c)). Our aims are: Firstly, to detect presence or more exactly absence of cracks on road surface to reduce the number of images that may be stored and shown to the operator. Secondly, to simplify work of the operator by guessing the cracks detected by our method of image processing.

In this paper, we also try to qualify the road "scanner" of $A M A C \cap$. In this paper, we present comparative results of our method on three types of road surface images:

- "Laborator" images

- Static photographs of roads

- Images acquired by AMAC $\AA$ in dynamic mode with real conditions (weather, shadows, )

The results compared on these different images, in addition, may confirm the quality of our acquisition system.

\section{PROBLEM OF ROAD CRACK DETECTION}

\section{A. Position of problem}

Detection of crack in the road surface image is not a "simple" edge detection problem [1] or a texture analysis problem due to:

- Firstly, various pavement textures that can be encountered on pavement surface images.

- Secondly, cracks are thinner than aggregate size and also the space between them (like we see in the Fig. 2(a))
- And finally, the distribution of aggregates in the pavement is strongly random. It hard to distinguish the changing of aggreates distribution with an appearance of a crack.

The general approach of the defect detection in textured surfaces is to find a "homogeneous" feature of "no defect" textures and to detect the differences caused by presence of a defect. There are several methods in literature for the detection of defects in textured surface reviewed in [5],[6] but most of these methods are for detection of defects on uniform or nearly uniform texture. In these studies, two important features of texture were usually used. These features are orientation and frequency of motifs in analyzed texture. None of these methods have succeeded in the problem of the crack detection on images of pavement.

\section{B. Characteristics of crack}

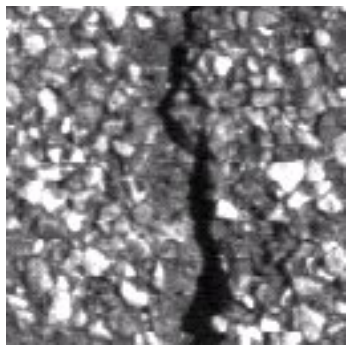

(a)

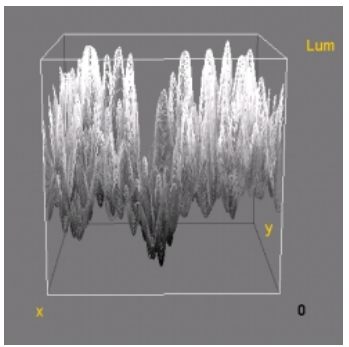

(b)

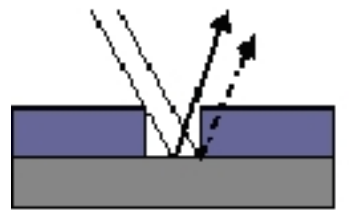

(c)

Fig. 3. Characteristics of crack: Crack on a strong texture surface (a), its 3D profile of grey level (b), model of illumination on a crack (c)

Fig. 3(b) shows us the 3D profile of an image of crack in a strong texture situation (Fig. 3(a)). Although the variation of grey level caused by the variation of texture is strong, geometrical specificity of cracks prevent the most part of light that comes into crack to be reflected to camera which capture the image (Fig. 3(c)). We suppose that the crack have two important characteristics:

- The grey level of cracked region is smaller than grey level of other regions of inspected images. It means that "crack" is a region darker than the others.

- A crack is a continuous region.

With these two hypotheses, we propose a simple method for the crack detection on road surface. The main idea of our method is that the crack is the darkest zone in the road image and appears continuous; others dark zones appear randomly and discontinuously.

\section{METHOD FOR CRACK DETECTION}

In this part, we describe our method for road surface cracks detection. This method can be separated into four steps present 


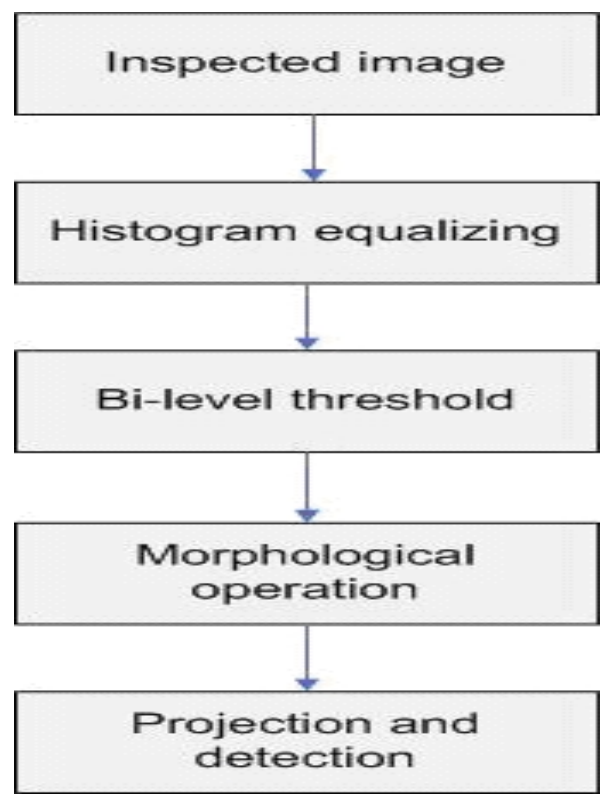

Fig. 4. Scheme of image processing method for road crack detection

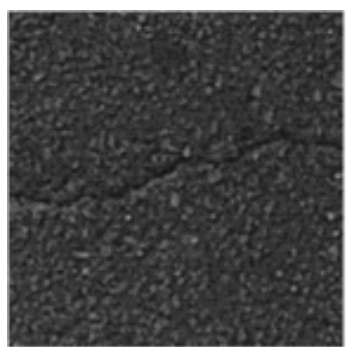

(a)

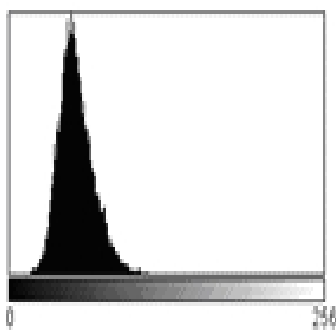

(c)

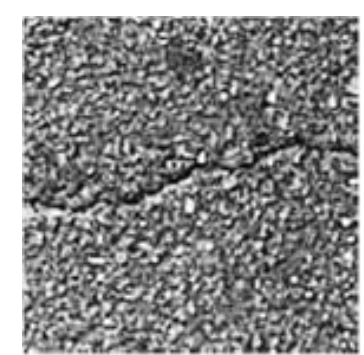

(b)

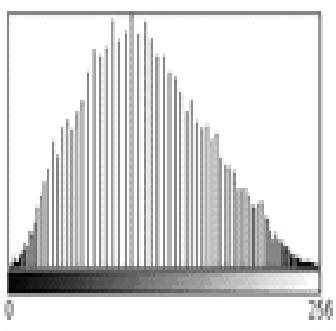

(d)
Fig. 5. Example of Histogram equalization on static image: original image (a), histogram equalized image (b), histogram of the image before and after equalization (c and d)

in general scheme in Fig. 4. Some results obtain at different steps are also given.

\section{A. Histogram equalization}

This first step is to improve the contrast of inspected image and to help thresholding in the next step, being less dependent on the illumination condition and the type of textures in road surface. An example of this operation is shown in Fig. 5.

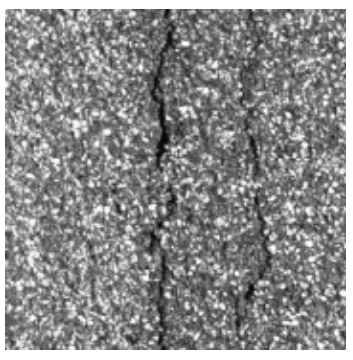

(a)

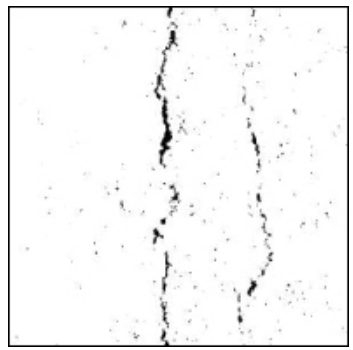

(c)

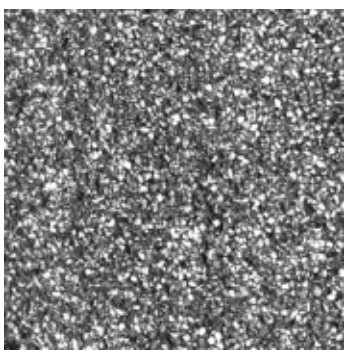

(b)

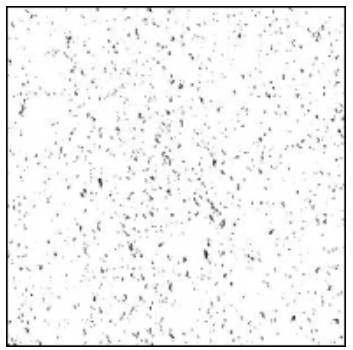

(d)
Fig. 6. An example of bi-level thresholding applied on two images: Image with crack and result of thresholding (a and c), image without defect and its thresholded result ( $b$ and $d$ )

\section{B. Bi-level thresholding}

After improving the contrast of inspected image, the cracklike pixels ${ }^{1}$ are detected by applying two thresholds $\left(t h r_{1}\right.$ and $\left.t h r_{2}, t h r_{2}>t h r_{1}\right)$ :

- The first threshold $t h r_{1}$ is used to detect the very dark pixels and mostly like crack pixels in the image.

- The threshold $t h r_{2}$ is then used and a pixel is labelled crack-like pixel when not only its grey level is greater than $t h r_{2}$ but also if it is spatially connected to a cracklike pixel previously detected by threshold $t h r_{1}$. This allows a reduction in detection of faults crack-like pixels.

The two thresholds $t h r_{1}$ and $t h r_{2}$ are choosen impirically for adapting to the type of road pavements.

\section{Morphological operation}

Fig. 6 presents an example of bi-level thresholding applied on two equalized images. One contains cracks and the other contains no defect. After thresholding, in the result of crack image, the crack-like pixels (darkest pixels in the image) appear in some continuous zones but in the result of the image without crack, the crack-like pixels appear randomly and discontinuously like noise. In this step, we, first, apply a "close" operation to connect the close pixels and then an "open" operation [7] to delete isolated pixels. These operations reduce the noisy (isolated) pixels and keep the crack (continuous) pixels.

\section{Projection and crack detection}

A simple operation is applied to the result image of the morphological step to decide if whether or not the image

\footnotetext{
${ }^{1}$ Pixels are guessed belonging to a crack
} 


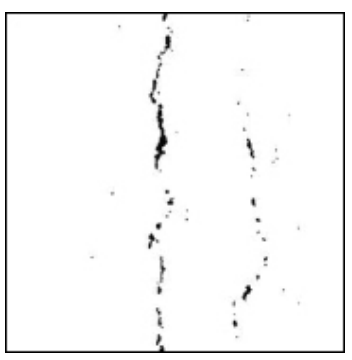

(a)

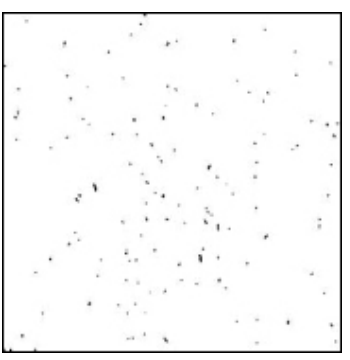

(b)
Fig. 7. An example of morphological results: Morphorlogical result of image in Fig. 6(c) and 6(d)

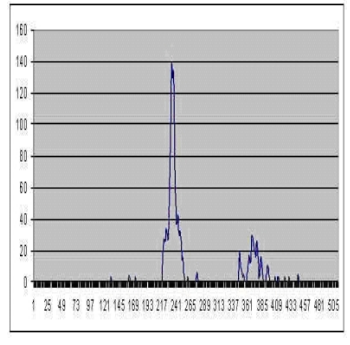

(a)

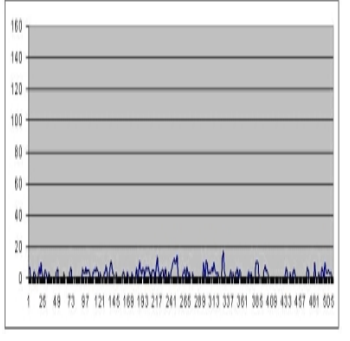

(b)
Fig. 8. Result of the projection on horizontal axis $\left(0^{\circ}\right)$ of image in Fig. 7(a) and on horizontal axis of image in Fig. 7(b)

contain a crack. The pixels of morphologic - result image are projected into four axes; $0^{\circ}, 45^{\circ}, 90^{\circ}$ and $135^{\circ}$. This technique is similar to the technique presented in [8]. If inspected image do not contain any defect, the distribution of dark regions is random. Projection results in different orientation will not present any high peak (Fig. 8(b)). Conversely, if inspected image contain a crack, at least, one or more very high peak will appear in projection results corresponding to alignment of crack pixels (Fig. 8(a)).

\section{RESULTS}

The process described above has been applied to a real set of images acquired by the vehicle AMAC $\AA$ on 12 kilometres of a motorway. The crack detection result is compared to expert classification. In this paragraph, results of our method on two others types of images are presented.

\section{A. Images used for the tests}

The images we use are 8 bits - greyscale images. There are three types of images used in these tests.

- The images acquired by AMAC®. These images were captured by the vehicle running on road. We call them 'dynamic images'. This set of images is captured in real

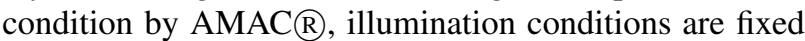
by laser illuminators on the vehicle.

- The images captured by a Kodak digital camera in static mode. A car is equipped with a fixed camera. It takes pictures at the stop. We call this set of images 'static images'. Captures of images have been made on sunny day but without any additional illumination: the lighting

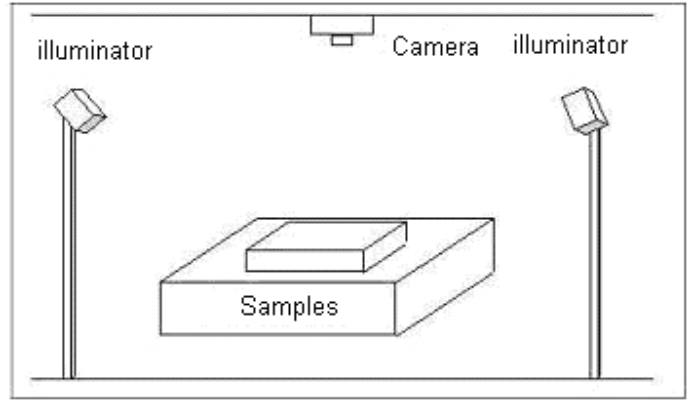

Fig. 9. Capture system of laboratory [9]

condition is not totally controlled and the captured images may contain some shadows.

- The images taken in laboratory with a fixed camera (Fig. 9), in ideal conditions of illumination. These images have been taken and presented in [9].

\section{B. Result of the detection of crack on dynamic images}

With the aims to filter the images without crack, not to store and not to show these images to the operator, TABLE I presents results. The percentage of fault alarm ${ }^{2}$ is high (12, $3 \%$ ) but the percentage of failure crack detection ${ }^{3}$ is very small $(0,17 \%)$. It is a good result for the purpose of the reduction no-crack images to be stored.

The processing time of our method on each image (4096x4096 pixels) is average 100 milliseconds. Currently, the method is implemented with $\mathrm{VC}++6$ using wxWidgets 2.8 , on Windows 2000 SP4, Intel Pentium 2,4 Ghz and 2 Gb RAM. It means about 10 images are processed per seconds. When the vehicle runs at speed of 80 kilometers per hour, each second it stores about 5 images. So our method can be implemented in real time.

TABLE I RESULTS ON AMAC $®$ IMAGES

\begin{tabular}{|c|c|c|l|l|}
\hline Image Type & $\begin{array}{c}\text { Number } \\
\text { of } \\
\text { images }\end{array}$ & Errors & $\begin{array}{l}\text { Percentage } \\
\text { of images } \\
\text { detected as } \\
\text { crack image }\end{array}$ & $\begin{array}{l}\text { Percentage of } \\
\text { images detected } \\
\text { as no-crack image }\end{array}$ \\
\hline No defect & 2318 & 286 & 12,3 & 87,7 \\
\hline Crack image & 516 & 5 & 99,0 & 1,0 \\
\hline Percentage of failure crack defection & \multicolumn{3}{|c|}{$0,17 \%$} \\
\hline \multicolumn{2}{|c|}{ Percentage of filtered images } & \multicolumn{3}{c|}{$71,7 \%$} \\
\hline
\end{tabular}

\section{Results on three images from different types}

Fig. 10 demonstrates the result of our method on three images from three containing similar cracks. In this test, the results on AMAC $(\mathbb{B}$ image and laboratory image are good due to good illumination condition and good position of camera. In both case we can see that cracks appear as a darkly continuous

\footnotetext{
${ }^{2}$ An image without crack but detected as a crack image

${ }^{3} \mathrm{An}$ crack image but detected as an image without crack
} 


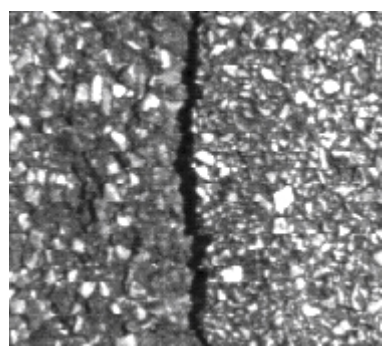

(a)

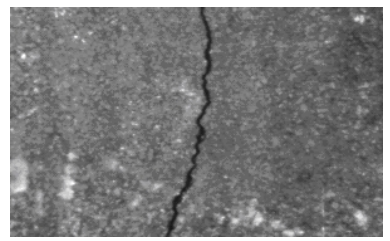

(c)

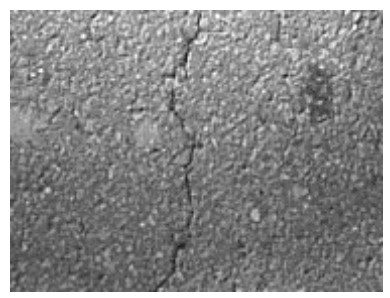

(e)

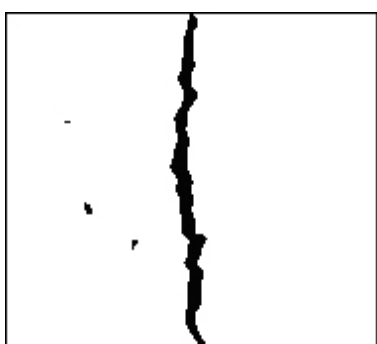

(b)

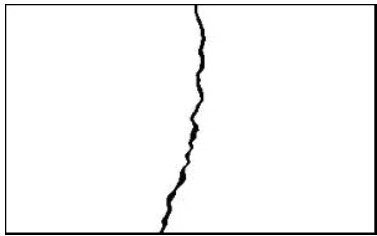

(d)

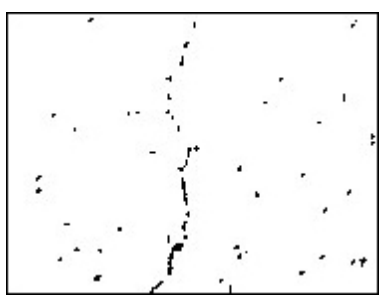

(f)
Fig. 10. Results on three images from three different types: AMAC dynamic image ( $a$ and $b$ ), laboratory image ( $c$ and $d$ ), static image (e and f).

zone. Results on static images are worse. Discontinuous crack pixels have been detected and there are many noisy pixels. Because of unevenly illuminated conditions and bad position of camera.

\section{CONCLUSION}

In this paper a low-complexity method used with AMAC $\mathbb{R}$ system has been presented. The results of the method on an acquisition session and its processing time show that the method is well enough and fast enough for filter no-crack images in real time. The results of step morphology can be used to help operator in decision and localization of cracks. Similar results of method on AMAC $\mathrm{A}$ 's dynamic images and laboratory images show that illumination conditions of AMAC $R$, thanks to laser illuminators, is as good enough as in laboratory images.

Further more, we plan to work with more quantified and qualified image database to characterize the capacity of our method on each type of texture, each type and each wide of cracks. These results enable us to qualify the surface road scanner of AMAC $\mathrm{R}$. We are developing others methods to take into account others kind of defects.

\section{ACKNOWLEDGMENTS}

The author would like to thank Jean Dumoulin and Central Laboratory for Roads and Bridges - LCPC, Bouguenais, France for their contribution to the laboratory image set.

\section{REFERENCES}

[1] Subirats, P.; Fabre, O.; Dumoulin, J.; Legeay, V. \& Barba, D.“A combined wavelet-based image processing method for emergent crack detection on pavement surface images", in 12th European Signal Processing Conference. 2004, Vienna, Austria.

[2] CSIRO Manufacturing Science \& Technology, RoadCrack Specifications, http://www.cmis.csiro.au/iap/RecentProjects/roadcrack.htm viewed on $20 / 10 / 07$

[3] Roadware Group Inc, Wisecrax data sheet, http://www.roadware.com/_lib/pdf/datasheet.wisecrax.pdf viewed on 20/10/07.

[4] Vectra's AMAC® specifications http://www.vectra.fr/AMAC.pdf.

[5] Kumar, A. \& Pang, G.K.H.Defect detection in textured materials using optimized filters Systems, Man and Cybernetics, Part B, IEEE Transactions on, Oct 2002, Vol.32, 553- 570.

[6] Kumar, A. Automated defect detection in textured materials, $\mathrm{PhD}$ thesis,University of Hong Kong, 2001.

[7] P. Soille, Morphological Image Analysis: Principles and applications, Springer, 1999.

[8] P. Subirat, Conception and validation of image processing method apply in the detection of crack in road surface image ,PhD thesis, University of Nantes, December 2006

[9] Subirats, P.; Dumoulin, J.; Legeay, V. \& Barba, D. "Automation of Pavement Surface Crack Detection using the Continuous Wavelet Transform" Image Processing, 2006 IEEE International Conference on, 2006, 3037 3040

Nguyen Tien Sy was born in Vietnam on October 30, 1978. He graduated from College of Technologies, Hanoi Vietnam in 2001, and Master of Science at Institute Polytechnics of Grenoble, France in 2006. His employment experience include: Researcher at College of Technology, Hanoi Vietnam from 2001 to 2003, and Researcher at CEA- Leti, Grenoble France from 2003 to 2005. His research interests include: Computer vision, image processing, machine learning, signal processing, and capture of movement. Tien Sy NGUYEN is now a PhD Student at PRISME Institute, Orleans University, France.

Manuel Avila born 16/07/1969. PhD in Automation \& Computer Science. Currently, he heads the Electronics \& Electrical Engineering department at the Institute of Technology of Chateauroux, Orleans University. His main research activities are in vision \& automation. PRISME Institute - TeamSEISME.

Stephane Begot born 30/07/1967. PhD in Automation. Currently, he's working in the Electronics \& Electrical Engineering department at the Institute of Technology of Chateauroux, Orleans University. His main research activities are in vision \& automation. PRISME Institute - Team- SEISME.

Jean Christophe Bardet was born in Limoges, France, in 1961. He received the M.S. Degree in electrical engineering from the University of Limoges, France, in 1984. From 1984 to 1994 he worked at IRCOM, Limoges, France and received his $\mathrm{PhD}$ degree in electronics in 1988. He has been working since 1994 at the Electronics \& Electrical Engineering department of the Institute of Technology of Chateauroux, Orleans University. Since 2006, he is director of the Institute. His main research activities are in vision \& automation. PRISME Institute - Team- SEISME. 